\title{
Analyses of molecular markers and leaf morphology of two rare birches, Betula obscura and B. pendula var. carelica
}

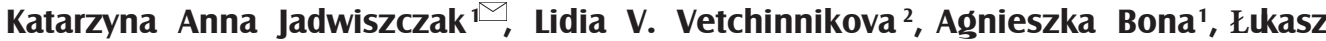 \\ Tyburski $^{3}$, Tatiana J. Kuznetsova², Valery A. Isidorov ${ }^{4}$
}

Jadwiszczak K.A., Vetchinnikova L.V., Bona A., Tyburski Ł., Kuznetsova T.J., Isidorov V.A., 2020 Analyses of molecular markers and leaf morphology of two rare birches, Betula obscura and B. pendula var. carelica. Ann. For. Res. 63(2): 121-137.

Abstract Trees and shrubs belonging to the Betula L. genus seem to represent one of the most confused interspecific relationships, and hybridization is considered to be one of the main factors responsible for the substantial genetic and morphological variation of birches. In the present investigation, the internal transcribed spacer ITS1 and ITS2 regions of nuclear ribosomal DNA, nuclear alcohol dehydrogenase $(A D H)$ gene sequences and amplified fragment length polymorphisms (AFLPs) as well as the Atkinson discriminant function (ADF) of leaf morphology were used to verify hypotheses concerning the origin of the dark barked Betula obscura and $B$. pendula var. carelica with the patterned wood. Both plants were considered by different authors to be distinct species, intraspecific forms of common B. pendula or $B$. pubescens, or hybrid taxa between $B$. pendula and $B$. pubescens. In the phylogenetic trees, the ITS and $A D H$ gene sequences of both $B$. obscura and $B$. pendula var. carelica clustered with those of $B$. pendula, whereas $B$. pubescens trees were somewhat distinct. In turn, the AFLPs revealed genetic similarity of $B$. pendula var. carelica to both frequent species, whereas B. obscura was clearly distinct from other birches. Values of the ADF indices of the rare birches were typical for $B$. pendula. In the light of the results obtained, we imply that B. obscura and $B$. pendula var. carelica represent an intraspecific variation of $B$. pendula, they are neither intraspecific taxa of $B$. pubescens nor hybrid species between the common birches. Different grouping of B. obscura in the AFLPs and DNA sequences analyses is likely a result of an unreliable phylogenetic signal of the former molecular markers.

Keywords: $A D H$ gene, AFLP, hybridization, ITS, morphological variation.

Addresses: ${ }^{1}$ Faculty of Biology, University of Białystok, Białystok, Poland

$\mid{ }^{2}$ Forest Research Institute, Karelian Scientific Center, Russian Academy of Sciences, Petrozavodsk, Russia ${ }^{3}$ Kampinos National Park, Izabelin, Poland| ${ }^{4}$ Institute of Forestry, Białystok University of Technology, Hajnówka, Poland 『 Corresponding Author: Katarzyna A. Jadwiszczak (kszalaj@uwb.edu.pl).

Manuscript received July 28, 2020; revised December 28, 2020; accepted December 28, 2020. 


\section{Introduction}

Hybridization is a process of interbreeding between individuals from genetically distinct populations. Hybridization is found to be frequent in the vascular plants characterized by differentiated genetic resources and spatial distribution, demography as well as ecological requirements (Whitney et al. 2010); thus, interspecific or interpopulation mixing can bring a high number of consequences, both positive and negative (Abbott et al. 2013). Positive hybridization outcomes involve the increase of overall genetic variation of mixing taxa or their adaptive abilities due to the transfer of neutral or selectively advantageous alleles across species boundaries (Rieseberg et al. 2007). This scenario is possible through backcrossing of the hybrids with their parental forms and is called introgression (Rhymer \& Simberloff 1996, Anamthawat-Jónsson 2019). It was revealed that introgression of new genetic variants could facilitate expansion of populations into new habitats (Ellstrand \& Schierenbeck 2006). It should be underlined, however, that introgression blurs the species boundaries to some extent. A negative outcome of hybridization/introgression is disruption of co-adapted local genes, which makes populations and species prone to extinction (Anamthawat-Jónsson 2019). This is especially distressing in the case of small, endangered populations lacking sufficient genetic variation necessary for an evolution of reproductive barriers (Ellstrand 1992).

Hybridization plays a very important role in the speciation process. Hybrid species can be formed with (auto- and allopolyploidy) or without (homoploid hybrid speciation) a change in the chromosome number. Polyploids immediately become reproductively isolated from the focal species as their gametes include a multiplied set of chromosomes (Abbott \& Rieseberg 2012). In homoploid hybrid species, reproductive isolation from the parental forms results from chromosomal rearrangements or novel traits that prevent backcrossing (Schumer et al. 2017). Since mixing taxa produce maladapted progeny, it is likely that selection against hybrids will reinforce reproductive barriers and finish the speciation process (Servedio \& Noor 2003).

Among vascular plants, one of the taxa most frequently involved in hybridization is the Betula L. genus (Whitney et al. 2010), and interspecific gene exchange is considered to be one of the main factors responsible for the substantial genetic and morphological variation in this group (Schenk et al. 2008, Ashburner \& McAllister 2016, Wang et al. 2016, 2020). There is no doubt that at least two Betula tree species occur in Europe: the silver birch (Betula pendula Roth) and the downy birch (Betula pubescens Ehrh.). Both types of birch trees are recognized as adaptable species due to their high genetic diversity and phenotypic plasticity, short generation time, ubiquity and resistance to environmental stress; thus, they seem to be perfect, although significantly undervalued, candidates for improving the resilience of the forest ecosystems and providing the sustainability of ecosystem functions and services (Beck et al. 2016, Dubois et al. 2020). As biodiversity at both within species and ecosystem levels is essential for the long-term resilience of ecosystem functions (Oliver et al. 2015), and hence, for the present and future human health, economy and development, it is very important to assess the contribution of the silver and downy birches to the forest ecosystem biodiversity.

The silver birch is diploid, while the downy birch is supposed to be allotetraploid derived from B. pendula and Japanese white birch Betula platyphylla Sukaczev (Wang et al. 2020). In the sympatric populations, the silver and downy birches can exchange genes, and interspecific hybrids are very often similar to one of the parental forms (Brown et al. 1982, Wang et al. 2014, Ashburner \& McAllister 2016, Bona et al. 2018). Within the ranges of 
the common B. pendula and B. pubescens, two rare birch trees can be found. These are the dark birch Betula obscura Kotula ex Fiek and the Karelian birch Betula pendula Roth var. carelica (Mercklin) Hämet-Ahti. Both birches are morphologically similar to $B$. pendula and $B$. pubescens, but some differences also exist. The most obvious features that differentiate $B$. obscura and B. pendula var. carelica from the both common species are dark bark and a patterned wood texture, respectively. In their natural habitats, both birch forms are found singly or in small groups within the stands of $B$. pendula and $B$. pubescens. The dark birch occurs in the central and eastern Europe (see Franiel 2009), the Karelian birch grows also in the northern part of the continent (Vetchinnikova \& Titov 2017).

In the past, $B$. obscura was classified as Betula verrucosa subsp. obscura (Kotula ex Fiek) Á. Löve \& D. Löve and Betula pendula var. obscura (Kotula ex Fiek) Olavská (see Govaerts 2017). Zaverukha (1964) presumed that $B$. obscura could be related to $B$. pubescens. Based on a greater angle of branch inclination, leaf morphology and lack of betulin in cork cells, it was suggested that $B$. obscura could be a separate species [see Franiel (2009) and references therein]. It was also assumed that B. obscura could be a synonym of Betula $\times$ aurata Borkh, a hybrid taxon between $B$. pendula and B. pubescens (Govaerts 2017). In Germany, most $B$. × aurata individuals exhibit brown or reddish bark (Gausmann \& Loos 2014). The origin of the birch with a patterned wood texture is also unclear. Most authors consider it to be either a variety (Ermakov 1986, Hämet-Ahti et al. 1992, Kosonen 2004) or a form of B. pendula (Ahokas 1985), but some have considered it as a distinct species (Lyubavskaya 1978, Pobirushko 1992, Vetchinnikova et al. 2013). Vetchinnikova and Titov (2017) proposed an ecogenetic hypothesis to explain the origin of the Karelian birch. According to this hypothesis, $B$. pendula var. carelica has appeared as a hybrid form in secondary introgression zone between closely related birch taxa. As the Karelian birch reveals an intermediate state of many morphophysiological traits between the silver and downy birches, these two species were supposed to be its potential progenitors (Vetchinnikova \& Titov 2017).

Using the internal transcribed spacer (ITS) regions of nuclear ribosomal DNA (ITS1 and ITS2), nuclear alcohol dehydrogenase $(A D H)$ gene sequences and amplified fragment length polymorphisms (AFLPs) as well as leaf morphology, we assessed the degree of genetic and morphological differentiation of the dark birch and Karelian birch to verify their relationships with the silver and downy birches. The following hypotheses were raised: 1) B. obscura is a distinct species, which has likely resulted from hybridization between $B$. pendula and $B$. pubescens, and 2) $B$. pendula var. carelica is the intraspecific taxon of the silver birch. The ITS regions were used previously in the studies of the Betula phylogeny; however, some interspecific relationships were unresolved or weakly supported ( $\mathrm{Li}$ et al. 2005, Nagamitsu et al. 2006, Bina et al. 2016, Wang et al. 2016). Thus, we compared the conclusions resulting from the studies of the ITS1 and ITS2 loci to those from other systems of molecular markers. The $A D H$ gene variation revealed clear differences between $B$. pendula and B. pubescens (Isidorov et al. 2014). AFLPs are widespread across the entire genome and more variable compared to nuclear sequences; thus, they were employed previously to discriminate birch species with different ploidy levels (Schenk et al. 2008, Eidesen et al. 2015, Bona et al. 2018). To investigate variation of leaf morphology, we calculated the Atkinson discriminant function (ADF; Atkinson \& Codling 1986), which was proven to be powerful for discriminating the silver and downy birch individuals (Wang et al. 2014, Bona et al. 2018). In addition, we summarized the available information on B. obscura and B. pendula var. carelica. 


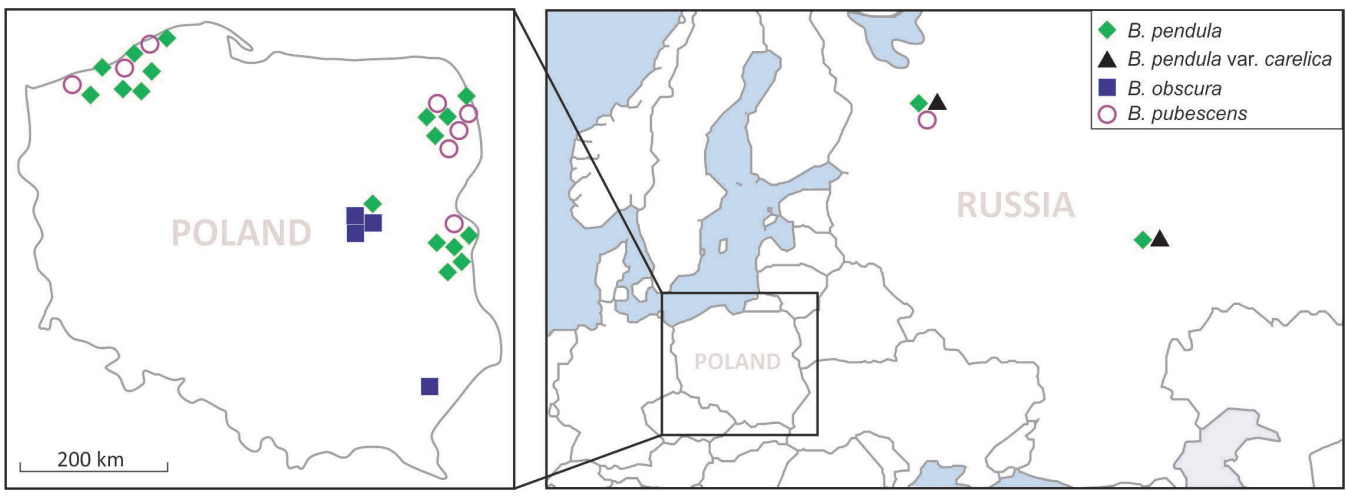

Figure 1 Geographical positions (Table 1S; Electronic Supplementary Material) of the B. pendula, $B$. pendula var. carelica, B. pubescens and B. obscura sampling sites in Poland and Russia

\section{Materials and Methods}

\section{Birch samples and DNA isolation}

In total, 66 individuals from four European Betula taxa were sampled (Table 1S; Electronic Supplementary Material). These taxa included both white-barked [B. pendula (29 individuals), B. pendula var. carelica (7 specimens) and $B$. pubescens (10)] and darkbarked B. obscura (20). North American river birch Betula nigra L. (8 individuals), with dark bark, was used for comparison. Among these species, $B$. pubescens was tetraploid with $2 \mathrm{n}=$ 56 , and the remaining specimens belonged to diploid species with $2 \mathrm{n}=28$ (Butorina 1985, Franiel 2009, Ashburner \& McAllister 2016, Tarieiev et al. 2019). As the dark birch was described in the territory of Poland for the first time (Fiek 1888, as cited in Tarieiev et al. 2019), it was sampled in most numerous stands located in Kampinos National Park (central Poland) and the "Black Birch in Reczpol" reserve (southeastern Poland) (Figure 1). Samples of $B$. pendula var. carelica were collected near Petrozavodsk (northwestern Russia) and Dzeržinsk (western Russia) to involve possible geographic differentiation of this birch. To assess genetic and morphological variation of the silver and downy birches, both species were derived from the different regions of Poland and two localities in Russia (Table 1S; Electronic Supplementary Material). With the exception of two specimens (Pen_Goj12 and Pen_Goj13), all of the Polish specimens of silver and downy birches were included in the molecular and morphological studies of Bona et al. (2018). Betula nigra was obtained from the living collections of the Botanische Gärten (Bonn, Germany), Royal Botanic Garden (Edinburgh, UK), Iowa State University (Ames, USA) and Arnold Arboretum of Harvard University (Boston, USA) (Table 1S; Electronic Supplementary Material). Leaf samples for DNA isolation were dried in silica gel before delivery to the laboratory. Total DNA was extracted using an AX Plant Kit (A\&A Biotechnology) according to the manufacturer's protocol after grinding with a TissueLyser LT bead mill (Qiagen).

To analyse variation in both the ITS1 and ITS2 regions, the studied sequences were compared with those found in GenBank for B. pendula (AJ006445, AM503889, JN247411, FJ011777, AY761127, AY352332, KT308990, KT308998, KT309000 KT309002, KT309006, KT309007), B. pubescens (KT308969, KT308970, KT308981, KT308982), B. pendula f. obscura (MH178103 - MH178109, MH231207 - MH231210, MH231213, MH231214, МH042912, МH042913, МH042917, MH042918, MH238474, MH238475, MH238477, MH238478, MK880215), and dwarf birch (Betula 
nana L.) (KT309018, KT309020; data not shown). However, the final ITS phylogenetic trees included only few GenBank sequences, from $B$. pendula (AJ006445, KT308990, JN247411), B. pendula $\mathrm{f}$. obscura (MH178108, MH178109), B. pubescens (KT308969, KT308970, KT308981), shrub birch (Betula humilis Schrk.) (KT309024, KT309026), B. nana (KT309018, KT309020) and B. nigra (KT308964).

For phylogenetic tree construction based on $A D H$ gene variation, the GenBank sequences of the following other birch individuals were included in the alignment: B. pendula (AJ535640, AJ549107), B. pubescens (AJ535645), B. nana (AJ535649), and B. humilis (KF466311, KF466322). Two ADH gene sequences of $B$. pubescens (Pub3A and Pub5A) that were described by Isidorov et al. (2014) and obtained from these authors upon request were also used.

\section{Sequencing and data analyses}

The ITS1 and ITS2 regions were amplified independently from 45 specimens (Table 1S; Electronic Supplementary Material) using the primer pairs ITS5 and ITS2 (Tarieiev et al. 2019) for the former locus and ITS3 and ITS4 (White et al. 1990) for the latter locus. The sequences of the $A D H$ gene were obtained from 33 birch individuals with the primers described by Järvinen et al. (2004). All sequences were amplified by PCR in a $5 \mu$ volume containing $2 \mu \mathrm{l}$ of diluted DNA (concentrations of 32$125 \mathrm{ng} / \mu \mathrm{l}), 1.69 \mu \mathrm{l}$ of Multiplex PCR Master Mix (Qiagen), $0.99 \mu$ of molecular H2O and $0.16 \mu \mathrm{l}$ of each primer at $0.2 \mathrm{mM}$ using a SensoQuest Labcycler (Biomedizinische Elektronik). The amplification of both the ITS1 and ITS2 loci was performed with the cycle profile obtained from A. Tarieiev upon request: an initial denaturation at $95^{\circ} \mathrm{C}$ for $15 \mathrm{~min}$ was followed by 35 cycles of $1 \mathrm{~min}$ at $95^{\circ} \mathrm{C}, 45 \mathrm{~s}$ at $55^{\circ} \mathrm{C}$ and $50 \mathrm{~s}$ at $72^{\circ} \mathrm{C}$, and a final extension step was performed for $20 \mathrm{~min}$ at $72^{\circ} \mathrm{C}$. With the exception of the annealing temperature, which was set at $57^{\circ} \mathrm{C}$, the PCR profile for the $A D H$ gene was the same as that described by Järvinen et al. (2004). The resulting amplification products were purified with a CleanUp kit (A\&A Biotechnology) and sequenced with the BigDye ${ }^{\mathrm{TM}}$ Terminator Cycle Sequencing Ready Reaction Kit (Applied Biosystems) using only the forward primer. The protocol for the sequencing reaction consisted of 25 cycles of $95^{\circ} \mathrm{C}$ for 20 $\mathrm{s}, 50^{\circ} \mathrm{C}$ for $15 \mathrm{~s}$ and $60^{\circ} \mathrm{C}$ for $1 \mathrm{~min}$. After the removal of unincorporated dideoxynucleotides with the help of the ExTerminator Kit (A\&A Biotechnology), the sequences were run on an ABI 3500 sequencer (Applied Biosystems). The GenBank accession numbers for the ITS and $A D H$ gene sequences are listed in Table $1 \mathrm{~S}$ (Electronic Supplementary Material).

The resulting amplification products were aligned in BioEdit v7.0.4 (Hall 1999) and refined manually. The GenBank B. pendula accessions AJ535640 and AJ006445 were used as reference sequences for the alignment of the $A D H$ gene and ITS regions, respectively. The coalescent-based Bayesian method (PHASE 2.1 algorithm) implemented in the DnaSP version 6.12.01 program (Rozas et al. 2017) was used to define the haplotypes of the amplified sequences of the $A D H$ gene. All ITS1 sequences were monomorphic. At most one variable site per sequence was found in the ITS2 region. Potential recombination events between haplotypes were checked independently for the ITS and $A D H$ loci in the RPD4 program (Martin et al. 2015) using different detection methods: MaxChi (Smith 1992), Bootscanning (Salminen et al. 1995), GENECONV (Padidam et al. 1999), SiScan (Gibbs et al. 2000), Chimaera (Posada \& Crandall 2001), RDP (Martin et al. 2005) and 3SEQ (Boni et al. 2007). The numbers of variable sites (parsimonyinformative sites and singletons) in the sequences were established with MEGA X_10.0.5 software (Tamura et al. 2007).

To investigate the relationships between the sequences, phylogenetic trees were constructed using the maximum likelihood (ML) and Bayesian inference (BI) methods. For the $A D H$ gene and ITS region analyses, the best-fit models of nucleotide 
substitution based on the Akaike information criterion (AIC) were $\mathrm{HKY}+\mathrm{G}$ (Hasegawa et al. 1985) and GTR+G (Tavaré 1986), respectively, as determined using MEGA (Tamura et al. 2007). The ML trees were inferred using the nearestneighbour-interchange (NNI) in MEGA, and their reliabilities were tested using bootstrapping with 1000 replicates. For BI analysis, the software MrBayes 3.2.6 (Ronquist et al. 2012) was used. In MrBayes, two independent runs were conducted (each with three heated chains and one cold chain) for 10 million generations, saving one tree every 1000 generations. After discarding the first $25 \%$ of runs as burn-in, a majority-rule consensus tree with posterior probabilities (PPs) was retrieved.

\section{AFLP fingerprinting and data analyses}

In total, 74 birch individuals were studied (Table 1S; Electronic Supplementary Material). The AFLP procedure followed Vos et al. (1995), with some modifications adopted from the Applied Biosystems protocol (AFLPTM Plant Mapping). In the initial test, four samples were used to screen polymorphism and reproducibility of 26 primer combinations. Then, two primer combinations (EcoRI-AGC/MseI-CAA and EcoRI-AGC/MseICTC) that resulted in clear amplification profiles were chosen for the analysis of all individuals. As we used the EcoRI-ACC/MseI-CAC profiles of 24 specimens of $B$. pendula and 8 of B. pubescens from the Polish populations (Bona et al. 2018), this primer combination was also prepared from the restriction-ligation stage for the remaining individuals in our study. The NED-labelled selective amplification products were mixed with the 500 LIZ Size Standard (Applied Biosystems) and separated on an ABI 3130 sequencer (Applied Biosystems). GENEMAPPER 4.0 software (Applied Biosystems) was used to analyse the AFLP profiles. Polymorphic loci only were taken into account, with fragments ( $\geq 100$ RFU) in the size range of 70-500 bp scored as present (1) or absent $(0)$, and a binary data matrix was constructed based on the band scores. To minimize techniquerelated and scoring errors, seven individuals (two
$B$. pendula, two $B$. obscura, one $B$. pendula var. carelica, one $B$. pubescens, and one $B$. nigra) were randomly selected from the whole data set and replicated for all primer combinations to calculate the error rate according to the method of Bonin et al. (2004).

The GenoDive 2.0b23 software package (Meirmans \& Van Tienderen 2004), which allowed us to position the forms with different ploidy levels together, was used to detect possible clones among the obtained AFLP genotypes and estimate pairwise genetic differentiation between five birch taxa using the $\rho$ (Rho) parameter, which is comparable between different ploidy levels (Meirmans et al. 2018). The most likely number of genetic clusters (K) was established in STRUCTURE v2.3.4 (Pritchard et al. 2000) based on the recessive allele model implemented for the analysis of polyploids and dominant data (Falush et al. 2007). In the STRUCTURE input file, each individual was formally coded as tetraploid, but lacking chromosome sets were assigned as 'missing data' in the case of diploid $B$. pendula, $B$. pendula var. carelica, B. obscura and B. nigra. Ten independent replicates for each value of $K$, which varied from 1 to 5, were run. Every run consisted of 100,000 burnin steps, followed by 1,000,000 iterations, without prior information on the population origin. An admixture model and correlated allele frequencies were used. To determine the optimal $\mathrm{K}$, the mean likelihood [LnP(D)] and standard deviation for each value of $\mathrm{K}$, as well as $\Delta \mathrm{K}$ values using the method of Evanno et al. (2005) were assessed in the STRUCTURE HARVESTER software (Earl \& vonHoldt 2012). Additionally, the STRUCTURE was also run five times for $\mathrm{K}=2$ to calculate the mean value of the cluster membership coefficient (Q) for each specimen of B. pendula, B. pendula var. carelica, $B$. pubescens and B. obscura. Individuals with $0.1<\mathrm{Q}<0.9$ were indicated as potential hybrids, the specimens with $\mathrm{Q} \geq 0.9$ or $\mathrm{Q} \leq 0.1$ were identified as pure species. Principal coordinate analysis (PCoA) in PAleontological STatistics (PAST) version 3.14 (Hammer et al. 2001) based on Jaccard's dissimilarity matrix (Kosman \& Leonard 2005) was carried out to highlight the 
genetic relationships between individuals studied. This analysis was also conducted without the $B$. pubescens specimens, which are tetraploid.

\section{Analyses of leaf morphology}

To calculate the ADF (ADF; Atkinson \& Codling 1986), taking into account the number of teeth between the third and fourth lateral nerves (LTF), the measurements of the distance from the petiole to the first tooth on the leaf base (DFT) and the leaf tip width (LTW), from 6-12 leaves per individual located at the second position of a vegetative short shoot were taken from all available trees.

\section{Results}

\section{Sequence analyses}

The final alignment of the combined ITS regions included 58 sequences. No evidence of recombination was found between ITS sequences. The total length of the combined ITS regions was 641 bp. Among these sequences, one variable character was observed at the ITS1 locus and four sites at the ITS2. All of these variable sites were parsimony informative.

As the sequences of $B$. nana from GenBank and Pub3A (Isidorov et al. 2014) were indicated to be recombinants at the $A D H$ locus by at least one detection method, these DNA fragments were excluded from the phylogenetic analyses. Thus, the final alignment consisted of $41 \mathrm{ADH}$ sequences, including 38 sequences from this study. The length of most amplified $A D H$ gene sequences ranged from 1013 to $1019 \mathrm{bp}$. The amplified fragment consisted of a partial $A D H$ gene sequence that extended from exon 2 to intron 5. Altogether, 29 variable sites were found: 23 parsimony-informative sites and 6 singletons. Among the parsimony-informative sites, one site was noted in the fourth exon and 22 sites were found in introns.

The ML and BI phylogenetic trees for particular DNA sequences were similar to one another; thus, only the former are shown. In the ITS phylogenetic tree, the B. nigra individual was clearly distinct from other samples (Figure 2).

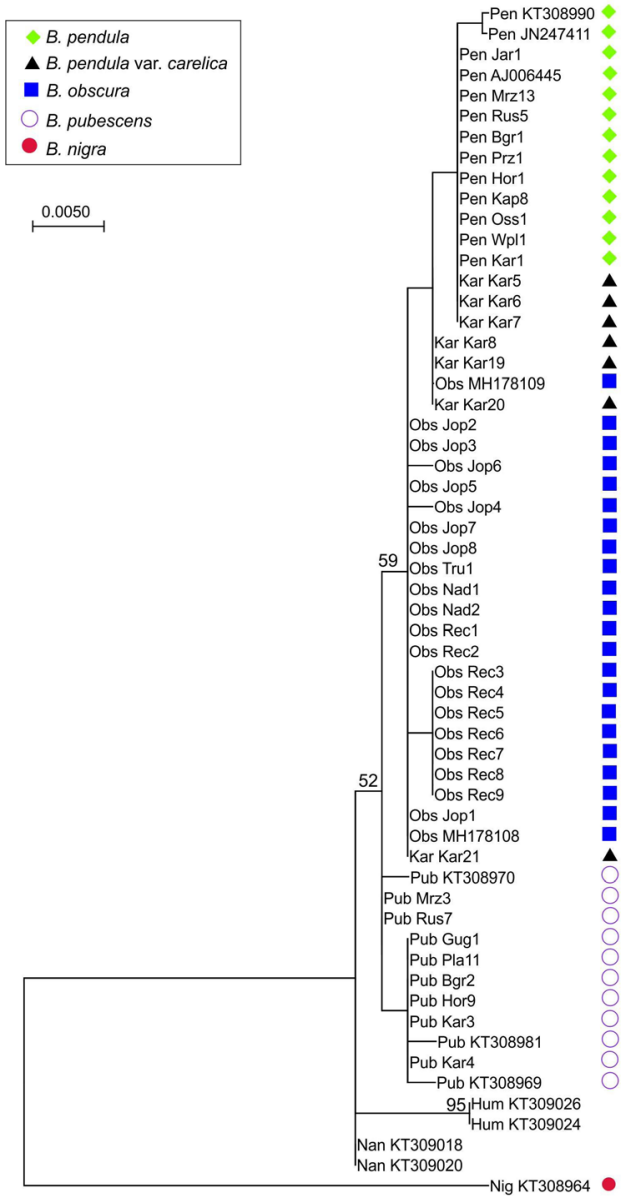

Figure 2 Maximum likelihood (ML) tree based on ITS sequences of different Betula species. The bootstrap values $\geq 50 \%$ are shown only ( 1000 replicates). Individual codes are according to Table 1S (Electronic Supplementary Material). GenBank accessions of: B. pendula (KT308990, JN2047411, AJ006445), B. pendula f. obscura (MH178109, MH178108), B. pubescens (KT308970, КT308981, КT308969), $B$. humilis (KT309026, KT309024), B. nana (KT308018, KT308020) and B. nigra (KT308964) are included 
The remaining samples were placed into a complex group. In this group, the $B$. nana and $B$. humilis specimens were outside of the tree birches. Position of $B$. humilis received strong bootstrap support (bs = $95 \%$ ). The $B$. pendula, B. obscura, and B. pendula var. carelica samples were intermixed within two subclusters (bs $=59 \%$ ). The $B$. pubescens individuals were distinct to some extent among the European Betula trees (bs = $52 \%$ ).

In the ML tree of the $A D H$ gene, three main groups were distinguished (Figure 3). The first group included all B. pendula, B. obscura and B. pendula var. carelica samples (bs $=99 \%$ ), which were subdivided into smaller subclusters. The second group consisted of the $B$. pubescens and $B$. humilis species. Two $B$. nigra samples were placed into a third group with $b s=100 \%$.

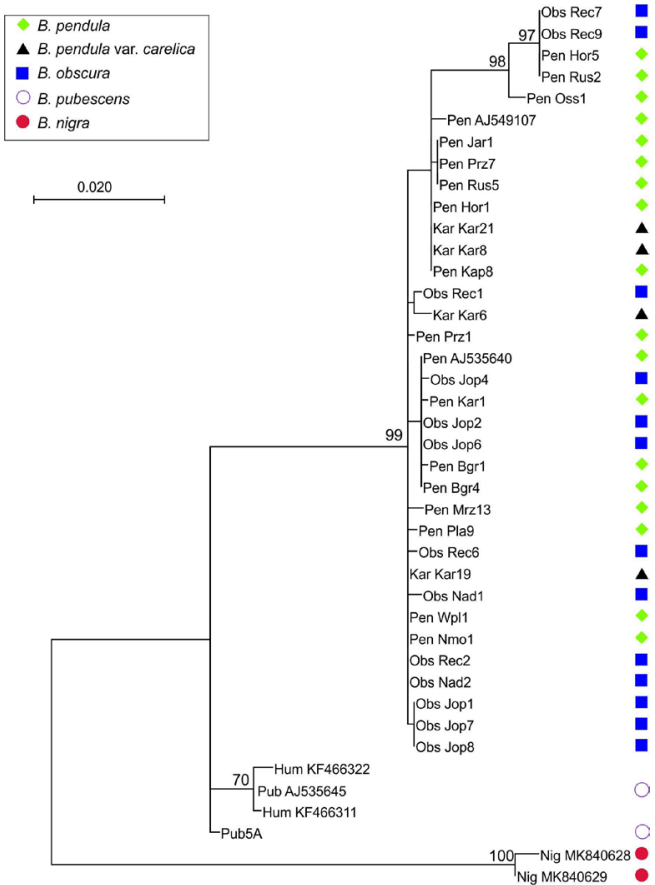

Figure 3 Maximum likelihood (ML) tree based on $A D H$ partial gene sequences of different Betula species. The bootstrap values $\geq 50 \%$ are shown only (1000 replicates). Individual codes are according to Table 1S (Electronic Supplementary Material). GenBank accessions of: B. pendula (AJ549107, AJ535640), B. humilis (KF466322, KF466311), B. pubescens (AJ535645) and $B$. nigra (MK840628, MK840629) are included. Pub5A - sequence of $B$. pubescens obtained from Isidorov et al. (2014)

\section{AFLP analyses}

AFLP scoring revealed 517 polymorphic loci: 190 from EcoRI-AGC/MseI-CAA, 109 from EcoRI-ACC/MseI-CAC and 218 from EcoRIAGC/MseI-CTC. The error rate was $3.6 \%$. No clones were found among the studied individuals.

The values of genetic differentiation between the birch taxa studied are presented in Table 2S (Electronic Supplementary Material). The highest genetic differentiation was observed between all European birch taxa and north American B. nigra $(\rho=0.388-0.441)$. Substantial genetic differentiation was also noted between $B$. obscura and the remaining birches from Europe ( $\rho=0.232-0.317)$. The lowest $\rho$ value was between the silver and Karelian birches (0.058).

In the STRUCTURE analysis, the posterior probability $\mathrm{LnP}(\mathrm{D})$ of the data increased steadily until three clusters (Figure 1S; Electronic Supplementary Material). The optimum number of genetically homogenous clusters in our dataset seemed to be $\mathrm{K}=3$, as the decrease in $\operatorname{LnP}(\mathrm{D})$ variation and the substantial increase of the standard deviation obtained for the 10 iterations was observed for $\mathrm{K}=4$. Using the Evanno' s et al. (2005) approach, the highest value of $\Delta \mathrm{K}$ was obtained at $\mathrm{K}=3$ (Figure $4 \mathrm{a}$ ). The first group was composed of white-barked individuals: $B$. pendula, $B$. pendula var. carelica and $B$. pubescens, the second included $B$. nigra, $B$. obscura individuals formed the third group. At $\mathrm{K}=2$, the clusters corresponded to the white- and dark-barked trees (Figure 4b). After exclusion of non-European B. nigra from the STRUCTURE analysis, four individuals (Pen_Bgr4, Pen_Hor2, Pen_Goj12 and Pen Goj13) of the silver birch, two specimens of the dark birch (Obs_Nad2 and Obs_Rec4) and one Karelian birch (Kar_Kar21) had Q-values between 0.1 and 0.9 (data not shown); thus, they could be of mixed origin. 
a

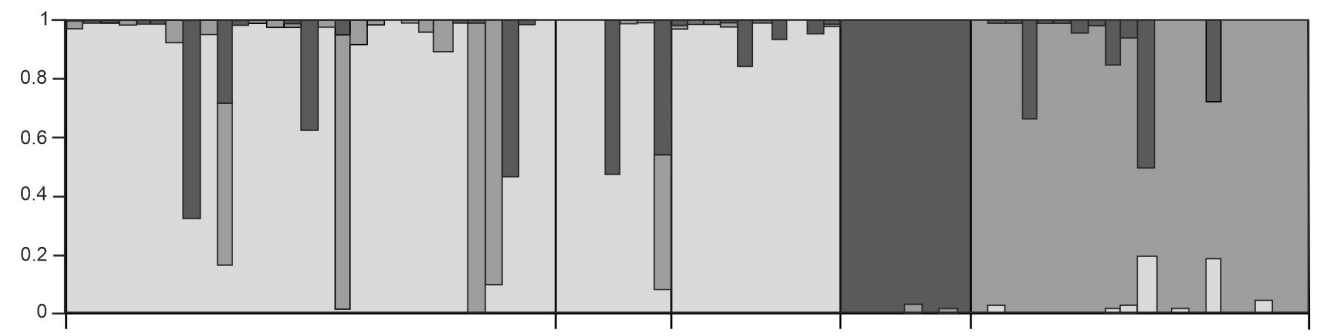

b

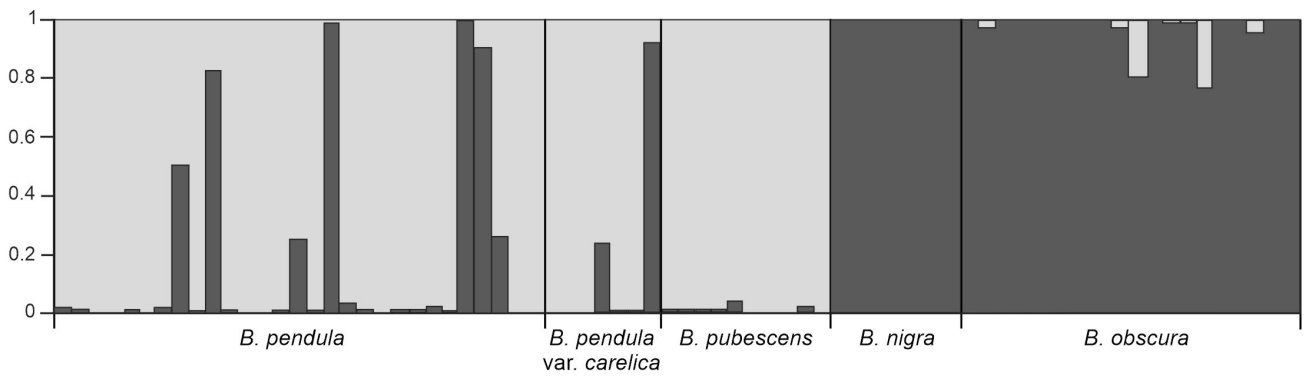

Figure 4 Bayesian clustering of the white (B. pendula, B. pendula var. carelica, B. pubescens) and dark barked (B. nigra, B. obscura) birch species based on 517 AFLP loci with (a) $\mathrm{K}=3$ and (b) $\mathrm{K}=2$

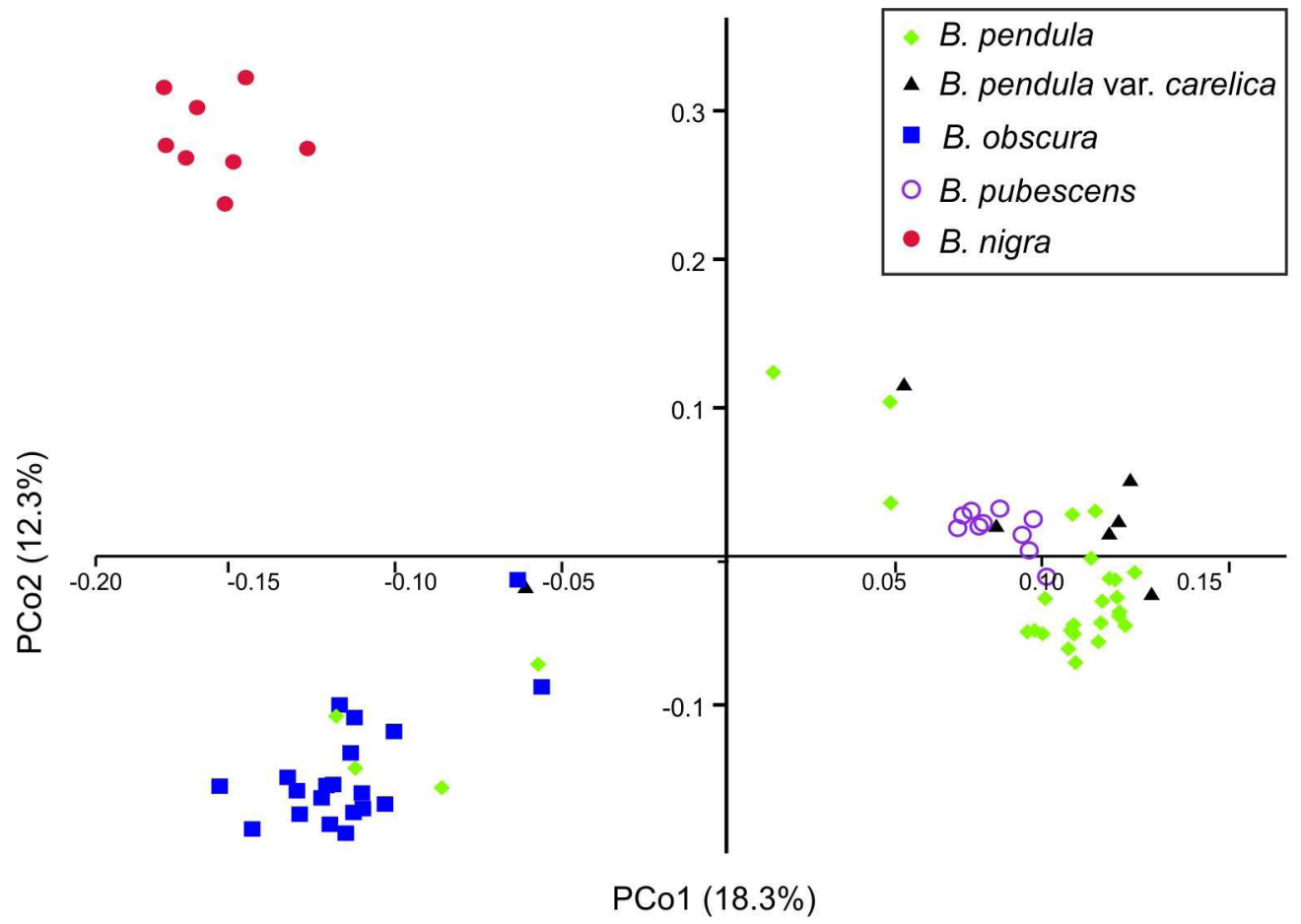

Figure 5 Principal coordinate analysis (PCoA) plot of 74 Betula samples using the Jaccard's similarity coefficients based on 517 AFLP loci 

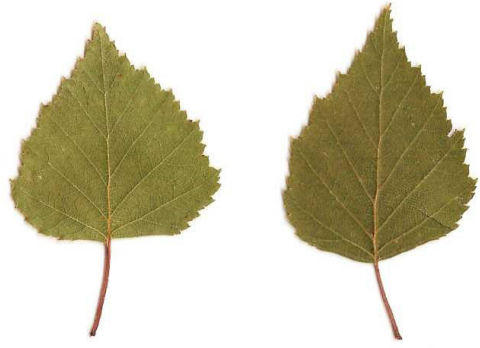

Pen_Hor2

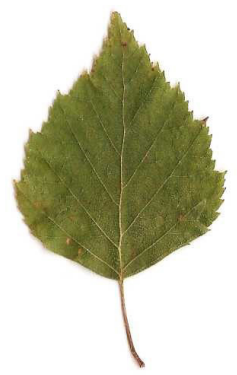

Pen_Goj12

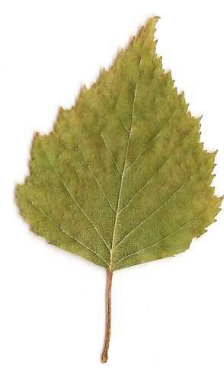

Pen_Goj13

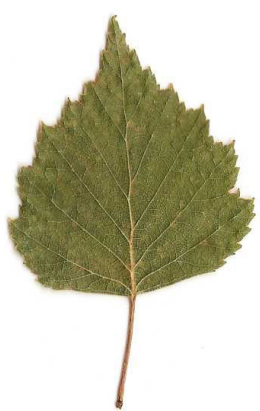

Obs_Jop1

$5 \mathrm{~cm}$

Figure 6 Leaf morphology of the B.pendula individuals (Pen_Bgr4, Pen_Hor2, Pen_Goj12, Pen_Goj13) that clustered together with the B. obscura specimens (exemplified by the Obs_Jop1 sample) in the PCoA based on 517 AFLP loci. Individual codes are according to Table $1 \mathrm{~S}$ (Electronic Supplementary Material)

The clustering of individuals was almost the same in the PCoA, regardless of whether the B. pubescens samples were included or not. Thus, the PCoA results for the five taxa are shown. This analysis revealed clear genetic dissimilarity between the white- and darkbarked birches (Figure 5). An exception was observed for one specimen of B. pendula var. carelica (Kar_Kar21) and four B. pendula specimens (Pen_Bgr4, Pen_Hor2, Pen_Goj12 and Pen_Goj13; Figure 6) that clustered with the dark-barked birches. Birches with dark bark B. obscura and B. nigra were also differentiated from each other. In this analysis, the first two axes explained 18.3 and $12.3 \%$ of the molecular variance, respectively.

\section{ADF scores}

The Atkinson discriminant function was calculated for two $B$. pendula individuals from central Poland, three B. pendula var. carelica individuals and nine $B$. obscura individuals (Table 1S; Electronic Supplementary Material). The ADF scores ranged from 4.84 to 18.68 , which were within the typical range for B. pendula (Atkinson \& Codling 1986, Wang et al. 2014, Bona et al. 2018).

\section{Discussion}

We investigated the variation of the ITS1 and ITS2 nuclear regions, partial nuclear $A D H$ gene sequences and 517 AFLP loci as well as leaf morphology to evaluate differentiation of the Polish B. obscura samples and B. pendula var. carelica collected in Russia in order to test their relationships with $B$. pendula and $B$. pubescens.

In general, the results of ITS and $A D H$ gene analyses were congruent; however, bootstrap support was higher for the $A D H$ gene sequences compared to the ITS data set. In the Betula phylogenies inferred from ITS data, a low bootstrap resulting from the small number of informative characters was demonstrated previously ( $\mathrm{Li}$ et al. 2005, Nagamitsu et al. 2006, Bina et al. 2016). All samples of the dark and Karelian birches formed wellsupported clades with $B$. pendula in both molecular analyses but were distinct from $B$. pubescens to some extent. North American $B$. nigra having dark bark was clearly separated from the European birches. In the ITS-based phylogenetic consideration of Wang et al. (2016) most of the silver birch subspecies were clustered together, whereas the downy birches were somewhat distinct. Tarieiev et al. 
(2019) demonstrated that two single nucleotide polymorphisms (SNPs), G/T and $\mathrm{C} / \mathrm{T}$, at the ITS1 and ITS2 loci, respectively, could be used to discriminate $B$. pendula and $B$. pubescens groups, although the discrimination power of the former SNP was higher than that of the latter. In the ITS1 and ITS2 regions of the birches studied, we found two diagnostic SNPs, described by Tarieiev et al. (2019). The silver, dark and Karelian birches are characterized by T alleles at both the ITS1 and ITS2 loci, whereas the downy birch exhibits $\mathrm{G}$ and $\mathrm{C}$ alleles at ITS1 and ITS2, respectively. Thus, the application of ITS and $A D H$ gene markers strongly implies that the Polish dark-barked and Russian patterned-wood birches are in fact intraspecific taxa of the silver birch, but do not confirm that both birches can be intraspecific forms of B. pubescens (Zaverukha 1964, Lyubavskaya 1978). Lack of isoquercitrin and luteolin 4'-glucoside, both flavonoids found in B. pubescens, in the B. obscura leaves also contradicts a close relationship between these two birches (Pawłowska 1982). Additionally, our phylogenetic investigations revealed that the birch trees with dark bark from Poland corresponded to B. kotulae Zaverucha (Zaverucha 1964) in Ukraine (Tarieiev et al. 2019). Thus, the possibility that the dark-barked birch trees in Poland and Ukraine belong to two distinct species, described previously as B. obscura and B. kotulae, respectively (Zaverucha 1964, Franiel 2009, Tarieiev et al. 2019), can be rejected. The same conclusion was suggested by Tarieiev et al. (2019), who compared the morphology of the B. kotulae holotype and Ukrainian B. kotulae individuals currently living and indicated that all of these samples represented the same taxon, which is called B. pendula f. obscura (Kotula ex Fiek) Tarieiev comb. nov.

The most obvious difference between B. obscura and both B. pendula and B. pubescens is the dark bark of the former tree. The dark colour is a consequence of a lack of thinwalled cork cells containing the triterpene betulin. Most B. obscura trees in Poland and Belarus have dark bark on the lower part of their trunks, but the colour gradually changes to light grey towards the top (Pobirushko 1992). Chemical and physical degradation tests showed that betulin was the most stable of the major components of the outer layer of birch bark (Godina et al. 2018); thus, it was hypothesized that the white colour evolved to reduce the risk of the overheating and scorching of the bark by low-angle sunlight at the high latitudes of the northern hemisphere (Ashburner \& McAllister 2016). Indeed, darkbarked birches, such as B. obscura in central Europe, occur at lower latitudes, while whitebarked species reach the northern boundary of forests on the Kola Peninsula. Single Karelian birch trees in Belarus are characterized by dark bark, whereas the white-barked populations are located in Karelia in Russia, Sweden and Finland (Vetchinnikova et al. 2013).

It seems unlikely that $B$. obscura is a synonym of $B . \times$ aurata, a hybrid form resulting from crosses between the silver and downy birches (Govaerts 2017). First, although B. × aurata individuals growing in Germany exhibit nonwhite bark, they are mainly triploid (Gausmann \& Loos 2014), as expected from crosses between diploid $B$. pendula and tetraploid $B$. pubescens. In the taxonomic treatment of Ashburner and McAllister (2016), B. × aurata is considered an interspecific hybrid, but there is no information about its bark colour. Betula obscura in Poland is diploid with 2 n $=28$ (Franiel 2009). Second, the F1 hybrids between B. pendula and B. pubescens included in the study of the composition of the volatile secretions of birch buds (Isidorov et al. 2019) had white bark, further demonstrating that the morphological resolution of $B$. pendula $\times B$. pubescens hybrids from individuals of pure species is often very difficult (Brown et al. 1982, Wang et al. 2014, Bona et al. 2018). Third, all $B$. obscura individuals in our study clustered together with $B$. pendula in both ITS and $A D H$ gene phylogenetic trees but were distinct from 
B. pubescens to some extent. Based on both the ITS $+5.8 \mathrm{~S}$ gene and the sequenced nuclear microsatellite $\mathrm{Bp} 09$, it was revealed that a recent hybrid species, the dwarf Japanese birch (Betula apoiensis Nakai), shared identical haplotypes with both of its parental species, Erman's birch (Betula ermanii Cham.) and dwarf bog birch (Betula ovalifolia Rupr.) (Nagamitsu et al. 2006). Taking into account the observations of Nagamitsu et al. (2006), we can also exclude a possibility that the Karelian birch can be a hybrid taxon between the silver and downy birches. The ITS and $A D H$ gene sequences of the Karelian birch represented the pattern of genetic variation typical for the silver birch only. No haplotype was shared with $B$. pubescens. Thus, the ecogenetic hypothesis considering an origin of $B$. pendula var. carelica as a result of hybridization between $B$. pendula and $B$. pubescens in the zone of secondary contact during the Little Ice Age (1300-1850; Vetchinnikova \& Titov 2017) is not confirmed.

Betula pendula var. carelica was indicated as a unique biological object, based on its habitat requirements (well-lit places, often less favourable for other tree species), extremely low competitive ability compared to other tree birches, variable growth forms (high- or short-trunked trees, bushes) and trunk-surfaces (ball-like thickened, small-tubercle or ribbed), patterned-wood texture (Vetchinnikova \& Titov 2020). However, decision not to give species status to the Karelian birch was based on a widespread uncertainty about its genetic origin, although generally accepted criteria of a species are complied (Vetchinnikova \& Titov 2020). In the controlled conditions, the proportion of progeny with wood features typical for the Karelian birch is $90 \%$, which can imply a stable pattern of inheritance (Vetchinnikova \& Titov 2020). Mashkina et al. (2011) suggested that both genetic (karyotypic abnormalities) and epigenetic (physiological changes in cells arising under extreme environmental conditions) factors were responsible for the development of patterned wood in the Karelian birch. The patterned texture results from the arrangement of the fibres at different angles rather than vertically, which is discernible from the presence of bulges on the trunk surface (Vetchinnikova \& Titov 2017).

Leaf morphology is a next feature that allows us to study the differences between the investigated birch forms. In our morphological analysis of leaves, the ADF values calculated for three $B$. pendula var. carelica and nine $B$. obscura specimens were higher than -2 ; i.e., they were within the typical range for $B$. pendula (Wang et al. 2014). This may indicate a closer relationship between the two birch forms and silver birch than downy birch. It has been reported that all leaves of $B$. obscura are wider and rounder than the leaves of silver birch (Hrynkiewicz-Sudnik 1962). We were not able to confirm the rounder shape of the dark birch leaves because appropriate measurements were not performed, but it seems likely that its leaf width is greater. In the ADF calculations, two parameters are related to leaf size: DFT and LTW (Atkinson \& Codling 1986). The mean values of these parameters for B. obscura were DFT $=12.4$ and $\mathrm{LTW}=11.3$, while mean values of DFT $=11.4$ and LTW $=$ 10.8 were obtained for the Polish silver birch samples (Bona et al. 2018). It must be stressed, however, that we analysed only a few samples of $B$. obscura. It would be valuable to examine whether the chemical composition of the bud exudates of $B$. obscura is similar to that of $B$. pendula. It was revealed that the differences in the composition of compounds in the bud exudates enabled to discriminate between $B$. pendula and B. pubescens (Isidorov et al. 2014, 2019).

Close relationship of $B$. obscura and $B$. pendula var. carelica with $B$. pendula rather than $B$. pubescens can be also supported by chromosome numbers. In general, $B$. obscura and $B$. pendula var. carelica are considered to be diploid with $2 \mathrm{n}=28$ (Butorina 1985, Franiel 
2009). This chromosome number is typical for the silver birch, in contrast to the downy birch, which is tetraploid with $2 \mathrm{n}=56$. However, among $B$. obscura individuals, approximately $17 \%$ of aneuploids were noted (Pobirushko 1992). In turn, the number of chromosomes in the cells of $B$. pendula var. carelica can vary from 23-25 to 40-42, which indicates the presence of mixoploidy in the somatic tissues of patterned individuals (Butorina 1985). According to Butorina (1993), wood patterning appears when contribution of mixoploid cells exceeds $30 \%$.

The most surprising result of our study was a clear genetic distinctness of the dark birch revealed by the AFLP markers. We noted substantial genetic differentiation between B. obscura and B. pendula $(\rho=0.232), B$. pendula var. carelica $(\rho=0.298)$ and $B$. pubescens $(\rho=0.317)$. The $\rho$ values were only slightly lower than those found between the shrub birch $B$. humilis and the silver $(\rho=$ $0.344)$ and downy $(\rho=0.333)$ birches (Bona et al. 2018). In turn, genetic differentiation between the Karelian and silver birches was low $(\rho=0.058)$. In the STRUCTURE analysis, white barked species: $B$. pendula, B. pendula var. carelica and $B$. pubescens were included in the first group. Dark-barked B. nigra trees formed the second group, while the B. obscura individuals formed a third group. The same grouping was shown in PCoA. However, some trees having the $\mathrm{Q}$ values between 0.1 and 0.9 were indicated at $\mathrm{K}=2$ (analysis without B. nigra) as being of a mixed origin. One of them was the Karelian birch Kar_Kar21. This individual represented a bush-like growth form, which is always associated with a lack of betulin in the bark. Although, the Pen Bgr4, Pen_Hor2, Pen_Goj12 and Pen_Goj13 specimens were white-barked trees, they are likely to include genetic admixture of the cluster represented by $B$. obscura, especially that Pen_Goj12 and Pen_Goj13 were sampled in the close vicinity to the locations of the dark birch in the Kampinos National Park.
In the previous AFLP investigation, the $B$. $\times$ obscura hybrid fell within the Group IVB. Betula, including B. pubescens but not $B$. pendula (Schenk et al. 2008). Unfortunately, the authors did not indicate the bark colour of this specimen. It was stated that results of phylogenetic investigations using the ITS sequences and AFLPs were generally congruent (Koopman 2005, Schenk et al. 2008). However, AFLP markers were found to be more efficient in describing relationships at both intra- and interspecific levels, for example in: woody bamboo (Phyllostachys Siebold \& Zucc. (Hodkinson et al. 2000), sweetpotato (Ipomoea batatas L.) (Huang et al. 2002), and globeflower (Trollius L.) (Després et al. 2003). Application of AFLPs to the phylogenetic studies of birches allowed to confirm that the species within subgenus Betula were highly similar to B. pendula (Schenk et al. 2008). Koopman (2005) suggested that AFLPs markers were most reliable at ITS divergence levels between 10 and 30-35 nucleotides in plants. In our study, five variable sites only were found in the ITS data set. According to Koopman (2005), phylogenetic signal can be unreliable at divergence levels below 10 ITS nucleotides, and we think that it can be a reason of discrepancy between the DNA sequences and AFLP results in our study.

Betula obscura and B. pendula var. carelica, like all members of the Betula genus, are anemophilous plants and reproduce mainly by seeds. The lack of clonal individuals of B. obscura in the Kampinos National Park and the "Black Birch in Reczpol" reserve in Poland indicates that these trees resulted from generative reproduction. All B. obscura trees sampled are tall and some of them produce flowers and seeds. As most of the Karelian birch trees are at a late generative and even post-generative stage of development, in practice, there is no viable understory within the entire geographical area (Vetchinnikova $\&$ Titov 2020). The flowering seasons of dark and silver birches as well as the Karelian and 
downy birches mostly overlap (HrynkiewiczSudnik 1962, Vetchinnikova \& Titov 2017). Thus, cross-pollination between numerically inferior B. pendula var. carelica and B. obscura and the common birches can cause dilution of their specific characters. Therefore, in the face of population declining of both birches, crossing with the widespread forms is a danger for the persistence of dark barked and patterned wood plants in natural conditions and reduces the overall biodiversity of the European forests (Vetchinnikova \& Titov 2017, 2020).

\section{Conclusions}

Our molecular analyses of the ITS and $A D H$ gene sequences revealed close relationships between the two rare birches, the dark-barked $B$. obscura and B. pendula var. carelica having the patterned wood texture, with the widespread $B$. pendula. No specimen investigated was grouped together with $B$. pubescens. There was no individual sharing haplotypes with both silver and downy birches. The ADF scores describing leaf morphology of the dark and Karelian birches were within the range of the silver birch. Thus, the results obtained strongly indicate that B. obscura and B. pendula var. carelica represent intraspecific variation of the silver birch, they are neither intraspecific taxa of $B$. pubescens nor hybrid species between $B$. pendula and B. pubescens. However, based on the AFLP genotypes, the dark birches were clearly distinct from other Betula trees. We suppose that the discrepancy between the AFLP and DNA sequences findings was caused by unreliable phylogenetic signal of the AFLPs that can be equivocal at low divergence level of the ITS regions (see Koopman 2005). In our opinion, both B. obscura and B. pendula var. carelica should be preserved, despite the lack of species status. These trees are picturesque elements of the European forests. Moreover, the wood of Karelian birch has long been used in the furniture and veneers industries as well as for producing unique gifts (Vetchinnikova
\& Titov 2020); thus, B. pendula var. carelica also has an economic value.

\section{References}

Abbott R., Albach D., Ansell S., Arntzen J.W., Baird S.J., Bierne N., Boughman J., Brelsford A., Buerkle C.A., Buggs R., et al., 2013. Hybridization and speciation. Journal of Evolutionary Biology 26: 229-246. DOI: 10.1111/j.1420-9101.2012.02599.x

Abbott R.J., Rieseberg L.H., 2012. Hybrid speciation. In: eLS. John Wiley \& Sons, Ltd: Chichester. DOI: 10.1002/9780470015902.a0001753.pub2

Ahokas H., 1985. Cytokinins in the spring sap of curly birch (Betula pendula f. carelica) and the non-curly form. Plant Physiology 118(1): 33-39. DOI: 10.1016/ S0176-1617(85)80162-0

Anamthawat-Jónsson K., 2019. Hybrid introgression: the outcomes of gene flow in birch. ScienceAsia 45: 203211. DOI: $10.2306 /$ scienceasia1513-1874.2019.45.203

Ashburner K., McAllister H.A., 2016. The Genus Betula: A taxonomic revision of birches. Kew Publishing, London.

Atkinson M. D., Codling A.N., 1986. A reliable method for distinguishing between Betula pendula and $B$. pubescens. Watsonia 7: 5-6.

Beck P., Caudullo G., de Rigo D., Tinner W., 2016. Betula pendula, Betula pubescens and other birches in Europe: distribution, habitat, usage and threats. In: San-MiguelAyanz J., de Rigo D., Caudullo G., Houston Durrant T., Mauri A. (eds.), European atlas of forest tree species. Publ. Off. EU, Luxembourg, pp. 70-73.

Bina H., Yousefzadeh H., Ali S.S., Esmailpour M., 2016. Phylogenetic relationships, molecular taxonomy, biogeography of Betula, with emphasis on phylogenetic position of Iranian populations. Tree Genetics \& Genomes 12: 84. DOI: 10.1007/s1129 5-016-1037-4

Bona A., Petrova G., Jadwiszczak K.A., 2018. Unfavourable habitat conditions can facilitate hybridisation between the endangered Betula humilis and its widespread relatives $B$. pendula and $B$. pubescens. Plant Ecology \& Diversity 11(3): 295-306. DOI: $10.1080 / 17550874.2018 .1518497$

Boni M.F., Posada D., Feldman M.W., 2007. An exact non-parametric method for inferring mosaic structure in sequence triplets. Genetics 176(2): 1035-1047. DOI: 10.1534/genetics.106.068874

Bonin A., Bellemain E., Eidesen B.P., Pompanon F., Brochmann C., Taberlet P., 2004. How to track and assess genotyping errors in population genetics studies. Molecular Ecology 13(11): 3261-3273. DOI: 10.1111/j.1365-294X.2004.02346.x

Brown I. R., Kennedy D., Williams D.A., 1982. The occurrence of natural hybrids between Betula pendula Roth and B. pubescens Ehrh. Watsonia 14: 133-145.

Butorina A. K., 1985. Tsitogenetika ekonomicheski vazhnykh form karel'skoy berezy [Cytogenetics of 
economically important forms of Karelian birch]. Genetika (Moscow) 21: 1192- 1198.

Butorina A. K., 1993. O prirode uzorchatosti drevesiny u karel'skoy berezy. In: Geneticheskiye i ekologicheskiye osnovy povysheniya produktivnosti lesov [On the nature of wood patterning in Karelian birch. In: Genetic and ecological basis for increasing forest productivity]. State University of Forestry and Technologies, Voronezh, Russia.

Després L., Gielly L., Redoutet B., Taberlet P., 2003. Using AFLP to resolve phylogenetic relationships in a morphologically diversified plant species complex when nuclear and chloroplast sequences fail to reveal variability. Molecular Phylogenetics and Evolution 27(2): 185-196. DOI: 10.1016/S1055-7903(02)00445-1

Dubois H., Verkasalo E., Claessens H., 2020. Potential of birch (Betula pendula Roth and B. pubescens Ehrh.) for forestry and forest-based industry sector within the changing climatic and socio-economic context of western Europe. Forests 11(3): 336. DOI: 10.3390/ f11030336

Earl D.A., vonHoldt B.M., 2012. STRUCTURE HARVESTER: a website and program for visualizing STRUCTURE output and implementing the Evanno method. Conservation Genetics Resources 4: 359-361. DOI 10.1007/s12686-011-9548-7

Eidesen, P.B., Alsos I.G., Brochmann C., 2015. Comparative analyses of plastid and AFLP data suggest different colonization history and asymmetric hybridization between Betula pubescens and B. nana. Molecular Ecology 24(15): 3993-4009. DOI: 10.1111/ mec.13289

Ellstrand N.C., 1992. Gene flow among seed plant populations. New Forests 6: 241-252. DOI: 10.1007/ BF00120647

Ellstrand N.C., Schierenbeck K.A., 2006. Hybridization as a stimulus for the evolution of invasiveness in plants? Euphytica 148: 35-46. DOI: 10.1007/s10681-0065939-3

Ermakov V.I., 1986. Mekhanizmy adaptatsii berezy k usloviyam Severa [Birch adaptation mechanisms to the conditions of the North]. Nauka, Leningrad, Russia.

Evanno G., Regnaut S., Goudet J., 2005. Detecting the number of clusters of individuals using the software STRUCTURE: a simulation study. Molecular Ecology 14(8): 2611-2620. DOI: 10.1111/j.1365294X.2005.02553.x

Falush D., 2007. Inference of population structure using multilocus genotype data: dominant markers and null alleles. Molecular Ecology Resources 7(4): 574-578. DOI: $10.1111 / \mathrm{j} .1471-8286.2007 .01758 . x$

Franiel I., 2009. Problemy taksonomiczne Betula obscura (Betulaceae) - przegląd literatury Fragmenta Floristica et Geobotanica - Series Polonica 16(1): 27-32.

Gausmann P., Loos G.H., 2014. Morphologie und Variationsbreite der Bastard-birke (Betula $\times$ aurata Borkh., Betulaceae) auf urban-industriell geprägten Standorten im Ruhrgebiet [Morphology and range of variation of the hybrid birch (Betula $\times$ aurata Borkh., Betulaceae) on urban-industrial locations in the Ruhr area]. Floristische Rundbriefe 47: 96-117.

Gibbs M.J., Armstrong J.S., Gibbs A.J., 2000. SisterScanning: a Monte Carlo procedure for assessing signals in recombinant sequences. Bioinformatics 16(7): 573-582. DOI: 10.1093/bioinformatics/16.7.573

Godina D., Paze A., Rizhikov J., Stankus K., Virsis I., Nakurte I., 2018. Stability studies of bioactive compounds from birch outer bark ethanolic extracts. Key Engineering Materials 762: 152-157. DOI: 10.4028/www.scientific.net/KEM.762.152

Govaerts R., 2017. WCSP: World Checklist of selected plant families (version Aug 2017). In: Roskov Y., Ower G., Orrell T., Nicolson D., Bailly N., Kirk P.M., Bourgoin T., DeWalt R.E., Decock W., van Niekerken E., Zarusshi J., Peney L (eds.), Species 2000 \& ITIS Catalogue of life, Available at www.catalogueoflife.org/ col. Species 2000: Naturalis, Leiden, the Netherlands. Accessed 27 Jul 2020.

Hall T.A., 1999. BioEdit: A user-friendly biological sequence alignment editor and analysis program for Windows 95/98/NT. Nucleic Acids Symposium Series 41: 95-98. DOI: 10.14601/Phytopathol_Mediterr14998 u 1.29

Hammer Ø., Harper D.A.T, Ryan P.D., 2001. Paleontological statistics software: package for education and data analysis. Palaeontologia Electronica 4(1): article4. 9.

Hasegawa M., Kishino H., Yano T., 1985. Dating of the human-ape splitting by a molecular clock of mitochondrial DNA. Journal of Molecular Evolution 22(2): 160-174. DOI: 10.1007/BF02101694

Hämet-Ahti L., 1992. Suomen puu- ja pensaskasvio. Dendrologian Seura r.y., Helsinki.

Hodkinson T., Renvoize S., Chonghaile G., Stapleton C.M.A., Chase M.W., 2000. A comparison of ITS nuclear rDNA sequence data and AFLP markers for phylogenetic studies in Phyllostachys (Bambusoideae, Poaceae). Journal of Plant Research 113: 259-269. DOI: 10.1007/PL00013936

Hrynkiewicz-Sudnik J., 1962. Zmienność i rozmieszczenie brzozy czarnej (Betula obscura A. Kotula) w Polsce [Variation and distribution of black birch (Betula obscura A. Kotula) in Poland]. Arboretum Kórnickie 7: 5-97.

Huang J., Corke H., Sun M., 2002. Highly polymorphic AFLP markers as a complementary tool to ITS sequences in assessing genetic diversity and phylogenetic relationships of sweetpotato (Ipomoea batatas (L.) Lam.) and its wild relatives. Genetic Resources and Crop Evolution 49: 541-550. DOI: 10.1023/A:1021290927362

Isidorov V.A., Stocki M., Vetchinnikova L., 2019. Inheritance of specific secondary volatile metabolites in buds of white birch Betula pendula and Betula pubescens hybrids. Trees 33: 1329-1344. DOI: 10.1007/s00468-019-01861-2

Isidorov V.A., Szczepaniak L., Wróblewska A., Pirożnikow 
E., Vetchinnikova L., 2014. Gas chromatographic-mass spectrometric examination of chemical composition of two Eurasian birch (Betula L.) bud exudates and its taxonomical implication. Biochemical Systematics and Ecology 52: 41-48. DOI: 10.1016/j.bse.2013.12.008

Järvinen P., Palmé A., Morales L. O., Lännenpää M., Keinänen M., Sopanen T., Lascoux M., 2004. Phylogenetic relationships of Betula species (Betulaceae) based on nuclear $A D H$ and chloroplast matK sequences. American Journal of Botany 91(11): 1834-1845. DOI: 10.3732/ajb.91.11.1834

Koopman W. J. M., 2005. Phylogenetic signal in AFLP data sets. Systematic Biology 54(2): 197-217. DOI: 10.1080/10635150590924181

Kosman E., Leonard K.J., 2005. Similarity coefficients for molecular markers in studies of genetic relationships between individuals for haploid, diploid, and polyploid species. Molecular Ecology 14(2): 415-424. DOI: 10.1111/j.1365-294X.2005.02416.x

Kosonen M., 2004. Visakoivu: Curly birch. Metsäkustannus Oy, Finland.

Li J., Shoup S., Chen Z., 2005. Phylogenetics of Betula (Betulaceae) inferred from sequences of nuclear ribosomal DNA. Rhodora 107(929): 69-86. DOI:10.3119/04-14.1

Lyubavskaya A.Ya. 1978. Karel'skaya bereza [Karelian birch]. Moscow: Publishing House Forest Industry.

Martin D.P., Murrell B., Golden M., Khoosal A., Muhire B., 2015. RDP4: detection and analysis of recombination patterns in virus genomes. Virus Evolution 1: vev003. DOI: $010.1093 /$ ve/vev1003

Martin D.P., Williamson C., Posada D., 2005. RDP2: recombination detection and analysis from sequence alignments. Bioinformatics 21: 260-262. DOI: 10.1093/ bioinformatics/bth490

Mashkina O.S, Butorina A.K., Tabatskaya T.M., 2011. Karelian birch (Betula pendula Roth. var. carelica Merkl.) as a model for studying genetic and epigenetic variation related to the formation of patterned wood. Russian Journal of Genetics 47(8): 951-957. DOI: 10.1134/S1022795411080126

Meirmans P.G., Liu S., van Tienderen P.H., 2018. The analysis of polyploid genetic data. Journal of Heredity 109: 283-296. DOI: 10.1093/jhered/esy006

Meirmans P.G., Van Tienderen P.H., 2004. GENOTYPE and GENODIVE: two programs for the analysis of genetic diversity of asexual organisms. Molecular Ecology Notes 4(4): 792-794. DOI: 10.1111/j.14718286.2004.00770.x

Nagamitsu T., Kawahara T., Kanazashi A., 2006. Endemic dwarf birch Betula apoiensis (Betulaceae) is a hybrid that originated from Betula ermanii and Betula ovalifolia. Plant Species Biology 21: 19-29. DOI: 10.1111/j.1442-1984.2006.00147.x

Oliver T.H., Heard M.S., Isaac N.J.B., Roy D.B., Procter D., Eigenbrod F., Freckleton R., Hector A., Orme C.D.L., ..., Bullock J. M., 2015. Biodiversity and resilience of ecosystem functions. Trends in Ecology \& Evolution
30(11): 673-684. DOI: 10.1016/j.tree.2015.08.009

Padidam M., Sawyer S., Fauquet C.M., 1999. Possible emergence of new geminiviruses by frequent recombination. Virology 265: 218-225. DOI: 10.1006/ viro. 1999.0056

Pawłowska L., 1982. Flavonoids in the leaves of Polish species of the genus Betula L. V. The taxonomic position on the basis of flavonoid composition. Acta Societatis Botanicorum Poloniae 51: 413-421.

Pobirushko V.F., 1992. Ekologo-biologicheskiye osobennosti i vnutrividovaya izmenchivost' nekotorykh vidov roda Betula L. na granitsakh arealov (v usloviyakh Belarusi) [Ecological and biological features and intraspecific variability of some species of the genus Betula L. at the boundaries of ranges (in Belarus)]. Ph. D. Thesis, Institute of Experimental Botany, National Academy of Sciences, Minsk, Belarus.

Posada D., Crandall K. A., 2001. Evaluation of methods for detecting recombination from DNA sequences: computer simulations. Proceedings of the National Academy of Sciences of the United States of America 98(24): 13757-13762. DOI: 10.1073/pnas.241370698

Pritchard J.K., Stephens M., Donnelly P., 2000. Inference of population structure using multilocus genotype data. Genetics 155: 945-959.

Rhymer J.M., Simberloff D., 1996. Extinction by hybridization and introgression. Annual Review of Ecology, Evolution, and Systematics 27: 83-109. DOI: 10.1146/annurev.ecolsys.27.1.83

Rieseberg L.H., Kim S.C., Randell R.A., Whitney K.D., Gross B.L., Lexer C., Clay K., 2007. Hybridization and the colonization of novel habitats by annual sunflowers. Genetica 129: 149-165. DOI: 10.1007/s10709-0069011-y

Ronquist F., Teslenko M., van der Mark P., Ayres D.L., Darling A., Höhna S., Larget B., Liu L., Suchard M.A., Huelsenbeck J. P., 2012. MrBayes 3.2: efficient Bayesian phylogenetic inference and model choice across a large model space. Systematic Biology 61(3): 539-542. DOI: 10.1093/sysbio/sys029

Rozas J., Ferrer-Mata A., Sánchez-Del Barrio J. C., Guirao-Rico S., Librado P., Ramos-Onsins S. E., Sánchez-Gracia A., 2017. DnaSP 6: DNA sequence polymorphism analysis of large datasets. Molecular Biology and Evolution 34(12): 3299-3302. DOI: 10.1093/molbev/msx248

Salminen M.O., Carr J.K., Burke D.S., Mccutchan F.E., 1995. Identification of breakpoints in intergenotypic recombinants of HIV type- 1 by Bootscanning. AIDS Research and Human Retroviruses 11(11): 1423-1425. DOI: 10.1089/aid.1995.11.1423

Schenk M.F., Thienpont C.N., Koopman W.J.M., Gilissen L.J.W.J., Smulders M.J.M., 2008. Phylogenetic relationships in Betula (Betulaceae) based on AFLP markers. Tree Genetics \& Genomes 4: 911-924. DOI: 10.1007/s11295-008-0162-0

Schumer M., Cui R., Rosenthal G.G., Andolfatto P., 2017. Reproductive isolation of hybrid populations driven by 
genetic incompatibilities. PLoS Genet 11(3): e1005041. DOI: 10.1371/journal.pgen.1005041

Servedio M.R., Noor M.A.F., 2003. The role of reinforcement in speciation: theory and data. Annual Review of Ecology, Evolution, and Systematics 34: 339364. DOI: 10.1146/annurev.ecolsys.34.011802.132412

Smith J. M., 1992. Analyzing the mosaic structure of genes. Journal of Molecular Evolution 34: 126-129. DOI: $10.1007 / \mathrm{BF} 00182389$

Tamura K., Dudley J., Nei M., Kumar S., 2007. MEGA4: molecular evolutionary genetics analysis (MEGA) software version 4.0. Molecular Biology and Evolution 24(8): 1596-1599. DOI: 10.1093/molbev/msm092

Tarieiev A., Olshanskyi I., Gailing O., Krutovsky K. V., 2019. Taxonomy of dark- and white-barked birches related to Betula pendula and B. pubescens (Betulaceae) in Ukraine based on both morphological traits and DNA markers. Botanical Journal of the Linnean Society 191(1): 142-154. DOI: 10.1093/botlinnean/boz031

Tavaré S., 1986. Some probabilistic and statistical problems in the analysis of DNA sequences. In: Miura R. M. (ed.), Some mathematical questions in biology - DNA sequence analysis. Providence (RI): American Mathematical Society, pp. 57-86.

Vetchinnikova L.V., Titov A.F., 2017. The origin of the Karelian birch: an ecogenetic hypothesis. Russian Journal of Genetics: Applied Research 7(6): 665-677. DOI: $10.1134 / \mathrm{S} 2079059717060144$

Vetchinnikova L.V., Titov A. F., 2020. The Karelian birch: a unique biological object. Biology Bulletin Reviews 10: 102-114. DOI: 10.1134/S2079086420020085

Vetchinnikova L.V., Titov A.F., Kuznetsova T.Yu., 2013. Karel'skaya bereza: biologicheskiye osobennosti, dinamika resursov i vosproizvodstvo [Karelian birch: biological features, resource dynamics and reproduction]. Petrozavodsk: KarNTs RAN.
Vos P., Hogers R., Bleeker M., Reijans M., van de Lee T., Hornes M., Frijters A., Pot J., Peleman J., Kuiper M., Zabeau M., 1995. AFLP: a new technique for DNA fingerprinting. Nucleic Acids Research 23(21): 44074414. DOI: 10.1093/nar/23.21.4407

Wang N., Borrell J.S., Buggs R.J.A., 2014. Is the Atkinson discriminant function a reliable method for distinguishing between Betula pendula and $B$. pubescens (Betulaceae)? New Journal of Botany 4(2): 90-94 DOI: 10.1179/2042349714Y.0000000044

Wang N., Kelly L., McAllister H.A., Zohren J., Buggs R.J.A., 2020. Resolving phylogeny and polyploid parentage using genus-wide genome-wide sequence data from birch trees. Project: Phylogenomics of Betula (Betulaceae). Available at: https:/www.biorxiv.org/ content/10.1101/2020.07.13.200444v1 Accessed 14 Dec 2020.

Wang N., McAllister H.A., Bartlett P., Buggs R.J.A., 2016. Molecular phylogeny and genome size evolution of the genus Betula (Betulaceae). Annals of Botany 117(6): 1023-1035. DOI: 10.1093/aob/mcw048

White T.J., Bruns T., Lee S., Taylor J., 1990. Amplification and direct sequencing of fungal ribosomal RNA genes for phylogenetics. In: Innis M.A., Gelfand D.H., Sninsky J.J., White T.J. (eds.), PCR protocols: a guide to methods and applications. New York: Academic Press.

Whitney K.D., Ahern J.R., Campbell L.G., Albert L.P., King M.S., 2010. Patterns of hybridization in plants. Perspectives in Plant Ecology, Evolution and Systematics 12: 175-182. DOI: 10.1016/j. ppees.2010.02.002

Zaverukha B. V., 1964. Novi ta ridkisni vydy berez ukrayins'koyi flory [New and rare species of birch of Ukrainian flora]. Ukrainian Botanical Journal 21(5): 78-86. 